\title{
Wind Related Faults on the GB Transmission Network
}

\author{
Kirsty Murray \\ Department of Electronic and Electrical Engineering \\ University of Strathclyde \\ Glasgow, UK \\ Kirsty.murray@strath.ac.uk
}

\author{
Keith R.W. Bell \\ Department of Electronic and Electrical Engineering \\ University of Strathclyde \\ Glasgow, UK \\ Keith.bell@strath.ac.uk
}

\begin{abstract}
There are current worries surrounding climate change and with some of the effects already being seen, such as a rise in coastal temperatures and more extreme weather, greater research into how society will be affected is required. With the possibility of increased frequency and intensity of adverse or extreme weather there is a concern that this will affect the reliability of the electricity transmission network in GB which currently suffers from regular faults with a significant percentage of them caused by adverse or extreme weather. The research discussed in this paper focuses on extreme and adverse weather and its effects on the GB transmission network using data supplied by the three transmission companies that own and operate the GB network: Scottish Power Ltd., National Grid plc. and SSE plc. It also presents the beginnings of a relationship between weather types, mainly focusing on wind, and weather related faults.
\end{abstract}

Keywords-GB Transmission Network, Adverse or Extreme Weather, Fault Outages

\section{INTRODUCTION}

Climate change is major issue in many areas such as energy sectors, government policies, manufacturing, business, and the automotive industry. According to the UK Climate Impacts Programme (UKCIP) [1] climate change consists of variations within the earth's average climate, usually over a long period (typically changes that have occurred since the early 1900s). Many argue that the climate change currently being experienced is due to a mixture of natural causes (interactions between oceans and the atmosphere, variations in solar activity and volcanic eruptions), that the planet has always experienced, and human contributions, with the release of greenhouse gases being the main human contributor. In 2007 the Intergovernmental Panel on Climate Change (IPCC) backed up these assertions, stating that climate has changed many times over the centuries but that most of the warming that has occurred in the past 50 years is attributable to human activities [2]. Some of these effects can already be seen, such as a rise in coastal temperatures and more extreme weather. While all the above effects require research into how they will affect the country, this research focuses on extreme weather and its effects on the GB electricity transmission network.
There are multiple examples of how adverse and extreme weather can affect power grids all over the world. In 1998 Canada experienced the 'Great Ice Strom' which hit an area spanning from Eastern Ontario to Southern Quebec and left more than 4 million people without power, some for over a month in sub-zero conditions. The damage caused by this storm also affected some areas of Maine and New York in the USA and cost over $\$ 3$ billion to repair. Wind storms Lothar and Martin hit France in December 1999 which left nearly 3.4 million homes without power for up to 17 days and the resulting repairs cost almost $€ 1.5$ billion. In Poland in November 2004, 3 of the 17 regions were hit with a major snowstorm which left over 0.5 million people without power for over 5 days and cost around $€ 20$ million to repair [4]. Events like these cause physical damage to equipment such as towers, poles and substations, which leads to long repair and restoration times and therefore leaves the system vulnerable to further faults. The effects of adverse weather in the UK are arguably starting to be witnessed with the severe wind storms that hit in December 2011, January 2012 and December 2013 and the snow storms that hit in March 2013. These might not have caused as much damage as the cases above but still caused power outages and disruptions for many people across the UK.

Work has previously been done in this area by industry and academia alike. The 2008 climate change act (CCA) required that the UK electricity supply industry reported on adaptation measures to deal with the effects of climate change, i.e. National Grid (NG, 2010) [5], The Office of Gas and Electricity Markets (Ofgem, 2011) [6], SSE (2011) [7], and Scottish Power Energy Networks (SP, 2011) [8]. The Energy Networks Association (ENA 2011) [9] also completed an adaptation report looking at the UK as a whole. The UK Meteorological (Met) Office's Hadley Centre [10], [11], [12] has also completed work for the GB power network operators on the risk of adverse effects on the network due to climate change. The Met Office's work, however, focussed mainly on the distribution network as it is easier to quantify the weather-related impact as fault outages usually directly lead to customer interruptions (due to the radial network topology). The transmission network, however, is highly meshed and overloads, instabilities and interruptions should not occur following a single fault making it harder to quantify the impact. Work reported in academic literature has tended to be less UK specific to 
date. Work by Ward (2013) [13] summarises many different effects of weather on Europe and North American grids and Koval, Shen and Chowdhury (2006) [14] looked at modelling severe weather outages on transmission lines in Alberta, Canada.

\section{INITIAL WORK}

\section{A. Date Sources}

Fault data was collected from the three transmission companies that own and operate the GB network (Scottish Power Ltd., National Grid plc. and SSE plc.) The date ranges for fault data varied according to the company as follows: SP: 1984-2012, SSE: 1986-2012, NG: 1996-2011. Ideally the following analysis would incorporate the asset ages and design standards in use when the assets were installed as different equipment may have been designed to withstand different levels of mechanical stress induced by meteorological conditions. This however, has not been completed for this study as the data was not available from system operator. The faults were categorised as either weather or non-weather, and the weather category was broken down according to weather type: "Lightning", "Snow, Sleet, Blizzard \& Ice", "Wind, Gales and Windborne Objects", "Salt, Condensation \& Corrosion", "Pollution, Mist and (Freezing) Fog", "Fire not due to Faults", "Other Weather" (Solar heat, earthquakes etc.) and "Unknowns". The "Unknown" weather faults have been classed as weather related by the company, but with no related weather type.

Apart from the "Unknown" faults there were other data limitations within the provided fault data and so work was needed to try to fill the gaps. Firstly, in order to help classify unknown weather faults, past weather data was collected from the British Atmospheric Data Centre (BADC). Two data sets were studied: Met Office - MetDB [15], and Met Office - MIDAS Land Surface Station Data [16]. The latitude and longitude of each fault with missing data had to be found and the weather data for the day and time the fault occurred was downloaded and filtered by latitude and longitude. The distance from the fault to the closest weather station which was recording at the time was determined. Any fault further than $50 \mathrm{~km}$ from the nearest recorded weather station was left marked as an "Unknown" weather fault, as it was judged that further than that, the weather at the station was not necessarily an indicator of the weather at the fault location. By looking at the stations within range of the fault, in many cases the weather type was clear - high winds and snowfall being obvious fault causing weather. If the weather causing the fault was not obvious from the station data then the fault was left as an "Unknown" weather fault.

A further limitation of the obtained data was the lack of Return to Service (RTS) times. For one network operator, the number of faults recorded with a completed return to service time was very low at only $8.08 \%$ out of 1670 weather related faults. Another $6.59 \%$ of the fault RTS records are incomplete and are missing either a date or time, leaving $85.33 \%$ of the weather-related faults missing both an RTS time and date. For the second network operator, $100 \%$ of RTS times were provided and for the final network operator, $94.82 \%$ of provided weather faults had a RTS time. In order to fill in the missing RTS data for all operators, a non-parametric probability distribution was created based on the known RTS times. This was then resampled to populate the missing RTS times, for each weather type as the RTS time can vary significantly depending on the weather that has caused the fault.

An initial comparison between weather and non-weather related faults showed on average a 50/50 split of fault numbers. The proportion of weather related faults differed from region to region with both a yearly and seasonal variation. "SSB \& Ice" and "Wind, Gale \& Windborne Objects" related faults tend to dominate the winter months, whereas "Lightning" faults tend to dominate the summer months as expected. Compared with weather faults, nonweather faults are relatively stable throughout the years while weather faults are unpredictable and can greatly vary from year to year.

\section{B. Weather Related Fault Rates}

The data that was provided by the transmission companies is from different sized networks as well as spanning different time periods meaning that in its original format the data was not comparable. In order to be able to compare the data it was normalised to a per year per 100 $\mathrm{km} / \mathrm{per} 100$ items of equipment format. Initially, this was completed for each equipment type. However, once the data was broken down into equipment types it was found that this was unfeasible for further analysis as some equipment types hardly have any weather fault occurrences, meaning that the numbers would be too small to extract meaningful results. Table 1 shows that the majority of weather faults occur on overhead lines (OHLs), which is what is expected and is where the remainder of this paper will focus. This table also demonstrates that over $90 \%$ of weather related faults for Company A and Company B occurred on OHLs whereas this figure is only $73 \%$ for Company C. A likely reason for this is the large number of equipment Unknowns contained within this data set and a larger number of weather related faults on other equipment types. There are three types of weather that have caused $85 \%$ of weather related faults: Lightning", "Snow, Sleet, Blizzard \& Ice" and "Wind, Gales and Windborne Objects". The number of faults that occur on other weather types is quite low and the remainder of this paper will focus on the top three causes.

Overhead line faults were further analysed to determine the fault rate on a per year per $100 \mathrm{~km}$ basis for each company, to allow for comparison. Table 2 shows the actual weather fault rates on overhead lines on a per year per 100 $\mathrm{km}$ basis for the three largest weather fault types, and the total for all weather faults. As expected the annual mean was skewed by the extreme values caused by 'one off events' whereas the median is more representative of a 'normal year'. A 'one off event' is one that causes multiple faults but currently doesn't occur regularly e.g. a large snow or wind storm. 
TABLE I. Percentage of Faults By EQuipment TyPe

\begin{tabular}{|c|c|c|c|}
\hline Company & \%OHL & \%Unknowns & \%Other Equipment \\
\hline $\mathrm{A}$ & $94.1 \%$ & $1.8 \%$ & $4.1 \%$ \\
\hline $\mathrm{B}$ & $90.0 \%$ & $0.1 \%$ & $9.9 \%$ \\
\hline $\mathrm{C}$ & $73.2 \%$ & $13.6 \%$ & $13.2 \%$ \\
\hline
\end{tabular}

TABLE II. OHL WEAHER FAULT RATES PER YEAR PER $100 \mathrm{KM}$

\begin{tabular}{|c|c|c|c|c|c|c|}
\hline Category & \multicolumn{3}{|c|}{ Mean per year per 100km } & \multicolumn{3}{c|}{ Median per year per 100km } \\
\hline Company & $\boldsymbol{A}$ & $\boldsymbol{B}$ & $\boldsymbol{C}$ & $\boldsymbol{A}$ & $\boldsymbol{B}$ & $\boldsymbol{C}$ \\
\hline Lightning & $\mathbf{0 . 4 3}$ & $\mathbf{0 . 2 7}$ & $\mathbf{0 . 2 9}$ & $\mathbf{0 . 3 6}$ & $\mathbf{0 . 2 0}$ & $\mathbf{0 . 3 0}$ \\
\hline SSB \& Ice & $\mathbf{0 . 4 7}$ & $\mathbf{0 . 4 1}$ & 0.03 & $\mathbf{0 . 1 8}$ & $\mathbf{0 . 0 6}$ & 0.00 \\
\hline $\begin{array}{c}\text { Wind \& } \\
\text { Gales }\end{array}$ & 0.38 & 0.55 & 0.12 & 0.20 & 0.14 & 0.05 \\
\hline Total & 1.34 & 1.33 & 0.55 & 1.19 & 0.67 & 0.55 \\
\hline
\end{tabular}

The effect of one-off events can be seen clearly in Table 2. There is a small difference between the mean and median for "Lightning" related faults for all three companies, suggesting lightning is quite consistent throughout the years. In contrast, for Company A and Company B, the difference between the mean and median for "SSB \& Ice" related faults is quite large suggesting that they occur in large numbers in only certain years, consistent with the fact that large snow storms do not occur every year.

\section{RELATIONSHIP BETWEEN PREVAILING WEATHER AND FAULT RATES}

The effects of climate change cannot be assessed solely by using historic fault rates alone, a baseline relationship between recent past weather type occurrences and weather related faults is required. This will allow the future effects of weather on the transmission network to be modelled. In order to develop this relationship it is necessary to understand the effect of current weather on the system. To do this the relationship between weather types and weatherrelated faults must first be investigated. In order to develop this relationship it must first be found what weather type is the main cause of each weather related fault i.e. a snow fault may have several weather features associated with it - like snowfall, snow depth or wind gusts - or a wind fault could be associated with mean wind speed or maximum wind gusts. It is important to determine which weather feature or features correlate the strongest with weather related fault occurrences.

In order to do this, each weather related fault must be matched to a weather value. To do this a data set of past weather data was required, which involved choosing a reanalysis data set or an observational data set. The past weather data set that was decided upon was reanalysis weather data. Although reanalysis data carries some uncertainties related to interpolating, it provides a fuller data set which is more desirable in this case. ERA-Interim data [17], [18] is the reanalysis weather data used and is the latest global atmospheric reanalysis produced by the European Centre for Medium-Range Weather Forecasts (ECMWF). Data is available from January 1970 until August 2013, is generally downloadable in 3 hour time steps (though this varies depending on the weather type) and the grid size can be altered to different resolutions, in this case the smallest grid squares were used to give as fine a resolution as possible. The first weather related faults to be investigated were "Wind, Gales and Windborne Objects".

\section{A. Wind Fault Correlation to Weather Type}

To identify trends and relationships between windrelated faults and the available wind data, the correlation between wind gusts and wind related faults, and also wind speed and wind related faults were first established. To determine these relationships it was necessary to look at the number of occurrences of each wind gust and wind speed and the number of occurrences that cause a fault. This was completed using weather data that coincided with the available fault data date ranges from 1984-2012 in Scotland, and 1996-2011 in England and only grid squares covering the UK were included. The range of wind gust values and wind speed values were split into bins and each occurrence and fault occurrence was counted.

The scatter graphs in Fig. 1 and Fig. 2 show the relationship between wind gusts, wind speed and the $\log$ (frequency of fault occurrence). There is a non-linear relationship between both wind gusts and wind speed and fault occurrences. This relationship is made the clearest when the data is transformed and the logarithm of fault occurrence is used. Both figures show the coefficient of the determination $\left(\mathrm{R}^{2}\right)$ for the quadratic curves used. It can be seen that there is a strong and similar correlation between fault occurrences and both wind gusts and wind speed.

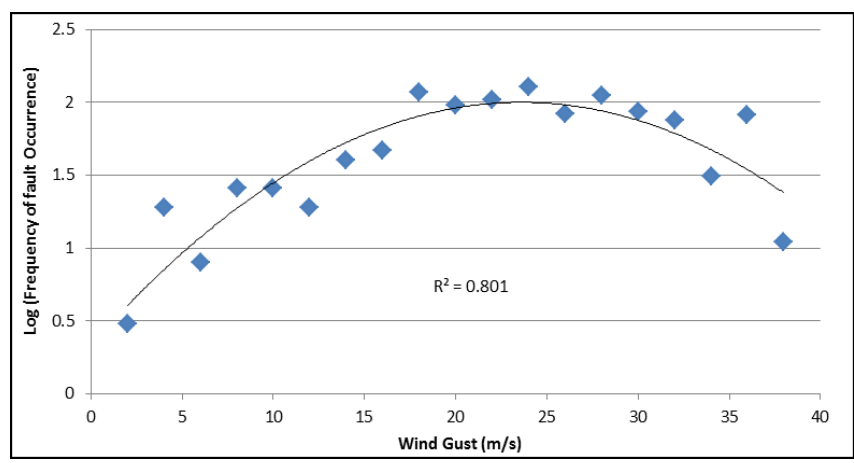

Fig. 1. Relationship between Fault Occurrences and 10meter Wind Gusts

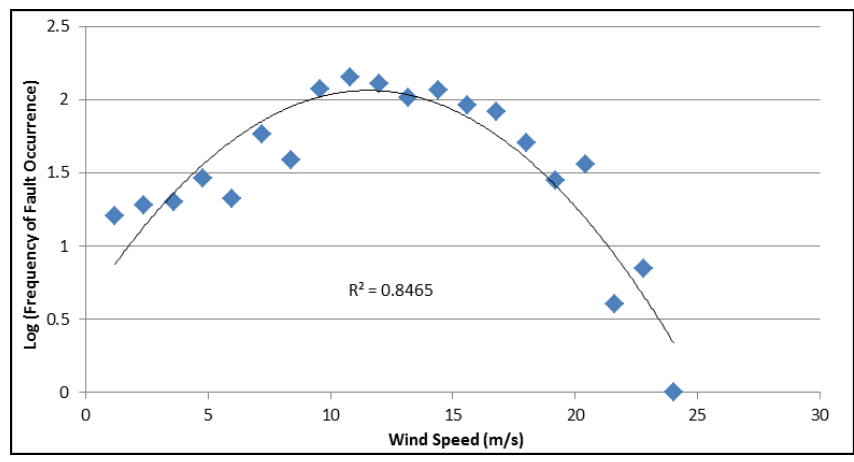

Fig. 2. Relationship between Fault Occurrences and 10meter Wind Speed 
It was decided to use wind gusts as the measure for wind faults as, while both have a similar coefficient of determination value, the wind gust correlation has less of a downwards trend towards the higher values and wind gusts are most commonly reported to be the main cause of wind related faults. For faults caused by other weather types, further analysis may be required in order to build the relational model and it may need to be constructed as a multivariate function of more than one weather feature. For example, the occurrence of snow faults may be caused by a combination of snowfall, snow depth, snow density or wind gusts.

\section{B. Wind Fault Relationship Example}

The range of wind gust values was initially split into one hundred bins. Then all occurrences within each bin were counted as well as the number of occurrences that caused a fault. One hundred bins however, proved to be too many for wind fault occurrences to see a clear relationship as there were a large number of bins with zero occurrences and so the number of bins was lowered to 20. From this a histogram of both wind gust occurrences and wind related fault occurrences were plotted and these can be seen in Fig. 3 and Fig. 4 along with the cumulative distribution functions for each data set. From Fig. 3 it is clearly shown that the majority of wind gust occurrences tend to be below $15 \mathrm{~m} / \mathrm{s}$ meaning that in general GB does not expected to experience wind gusts above this value. However from Fig. 4 it is seen that the majority of wind related faults occur above $15 \mathrm{~m} / \mathrm{s}$.

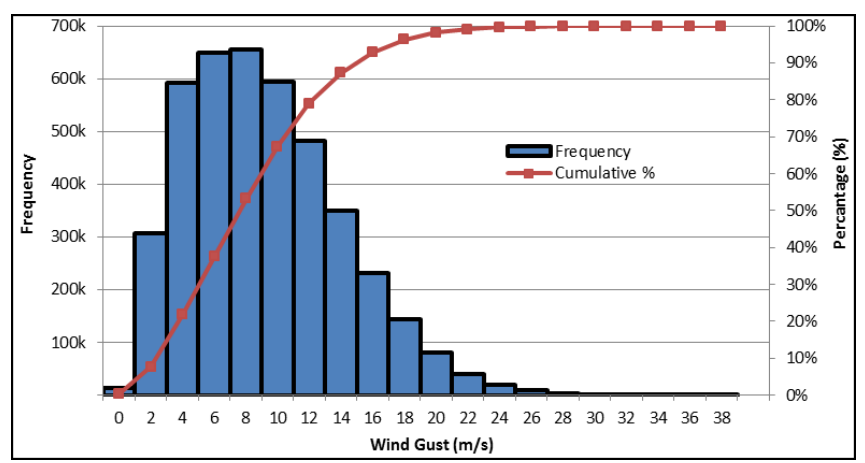

Fig. 3. Histogram and Cumulative Distribution Function for $10 \mathrm{~m}$ Wind Gust Occurrences

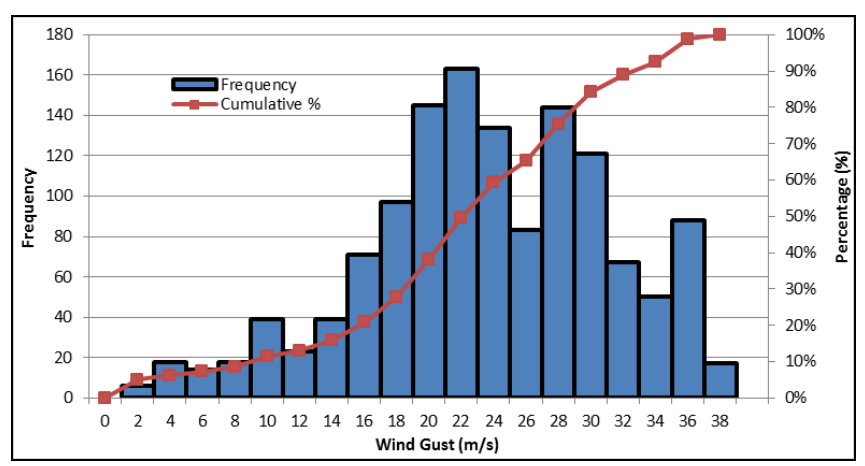

Fig. 4. Histogram and Cumulative Distribution Function for Wind Faults

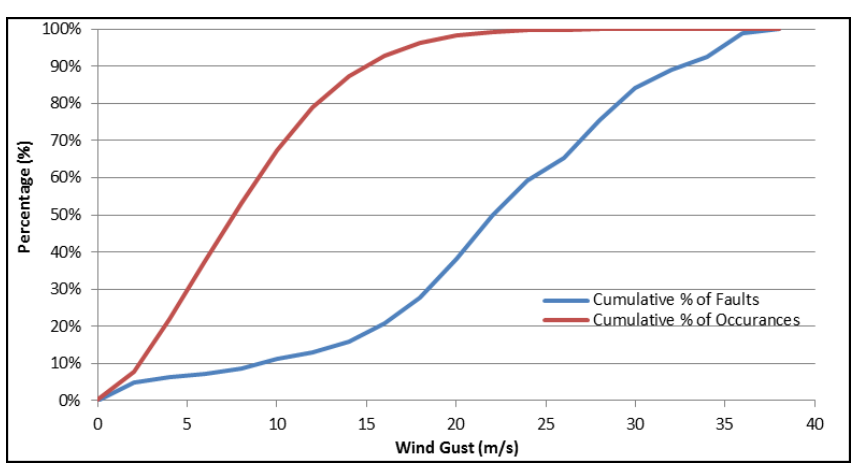

Fig. 5. Cumulative Distribution Function for Wind Faults and $10 \mathrm{~m}$ Wind Gust Occurrences

This shows that the system is designed to deal with the lower wind gusts more commonly seen in GB but that it is not designed to deal with the extremes or adverse conditions that can occur and that when they do occur there are faults on the system. The cumulative density functions for the data sets were then plotted on the same figure as shown in Fig. 5. This figure highlights that $66 \%$ of wind-related faults coincide with the occurrence of the top $1 \%$ of wind gusts. It also shows that $90 \%$ of faults occur in the top $20 \%$ of wind gusts. Fig. 3, Fig. 4 and Fig. 5 show the initial steps to developing the relationships between wind gusts and wind related faults.

\section{Wind Fault Probabilities}

The next stage of this relationship is to determine the probability of a fault occurring if a wind gust within a bin occurs. This is an important feature as it will allow changes to the wind gust occurrences to be made and see what the effects will be on the fault numbers and in turn the overall fault rate and security of the network. Using Bayes' theorem to calculate this probability:

$$
P(A \mid B)=\frac{P(B \mid A) \times P(A)}{P(B)}
$$

Where $\mathrm{P}(\mathrm{A} \mid \mathrm{B})$ is the probability of a wind related fault occurring based on a wind gust within the bin occurring. $\mathrm{P}(\mathrm{B})$ is the probability of a wind gust in each bin occurring based on historical records. $\mathrm{P}(\mathrm{B} \mid \mathrm{A})$ is the total number of faults occurrences in each bin divided by the total number of occurrences over all bins and $\mathrm{P}(\mathrm{A})$ is the fault rate for wind related faults. When calculating $\mathrm{P}(\mathrm{A})$ it was necessary to take into account the number of wind related faults that occur that are not classed as wind related, i.e. they were miss reordered. As previously mentioned, there are a proportion of faults that are classed as weather related but the exact cause is unknown. It was decided to split these "Unknown" weather faults between the other weather related fault categories by the ratio that already exists within the historical fault data. This split is shown in Table 3. 
TABLE III. UNKNOWN WEATHER FAULT SPLIT NUMBERS

\begin{tabular}{|c|c|c|c|}
\hline Category & Count & Ratio & Unknown Addition \\
\hline Lightning & 1622 & 0.35 & 91 \\
\hline SSB \& Ice & 1172 & 0.25 & 66 \\
\hline $\begin{array}{c}\text { Wind \& } \\
\text { Gales }\end{array}$ & 1401 & 0.3 & 78 \\
\hline $\begin{array}{c}\text { Other } \\
\text { Weather }\end{array}$ & 465 & 0.1 & 26 \\
\hline Total & 4660 & 1 & 261 \\
\hline
\end{tabular}



Fig. 6. Probability of a Fault Occurring for each 10meter Wind Gust

Once these values were all calculated it allowed for the probability of a wind related fault occurring based on a wind gust within each bin occurring to be calculated. The results are shown in Fig. 6. From Fig. 6 it can be see that there is a logarithmic trend to the probabilities i.e. as the wind gusts increase as does the probability of a fault occurring. This figure also shows that if the wind gust occurrence distribution shown in Fig. 3 were to move or skew to the right, the probability of a wind related fault occurring would be quite high which could be a problem to system reliability. It also shows the coefficient of the determination $\left(R^{2}\right)$ for this logarithmic fit. This value means that $97 \%$ of the variation of the probability of a wind fault occurrence is caused by the magnitude of the $10 \mathrm{~m}$ wind gust.

\section{Relationship Between Return to Service Times (RTS) \& Weather Faults}

One issue studying faults on the transmission network is that it is hard to quantify the impact on the system as it is highly meshed and multiple faults are required in order to create a customer interruption. It was thought that one possible method of quantifying the impact would be to look at if there was an obvious relationship between wind gusts and duration of wind related faults i.e. how long from the fault occurring till the fault was fully restored. The average duration for each bin was calculated but no obvious relationship was found as shown in Fig. 7.

There could be many reasons why this relationship isn't initially obvious if there is a relationship at all. Wind related faults tend to have a small RTS time as most of the faults are transient and so an auto-reclose will rectify the fault, meaning a low RTS time no matter what the wind gust was so there would be no relationship between fault duration and wind gusts if these lower duration values are included in the analysis.

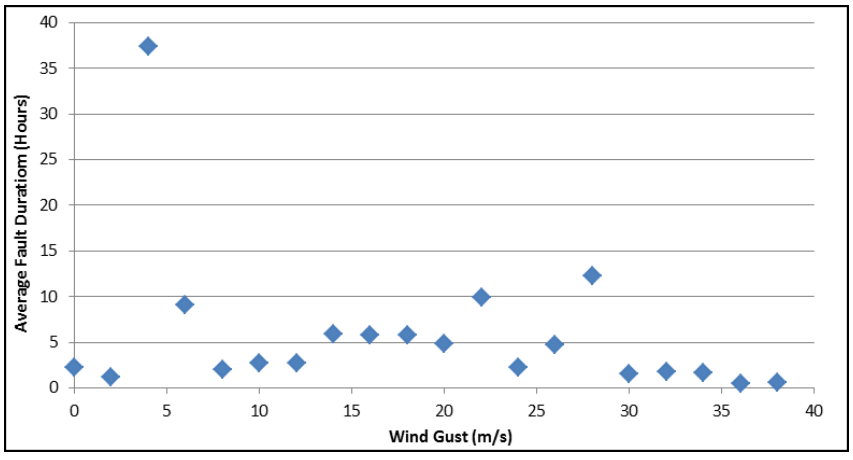

Fig. 7. Relationship between Average Fault Duration and 10meter Wind Gust

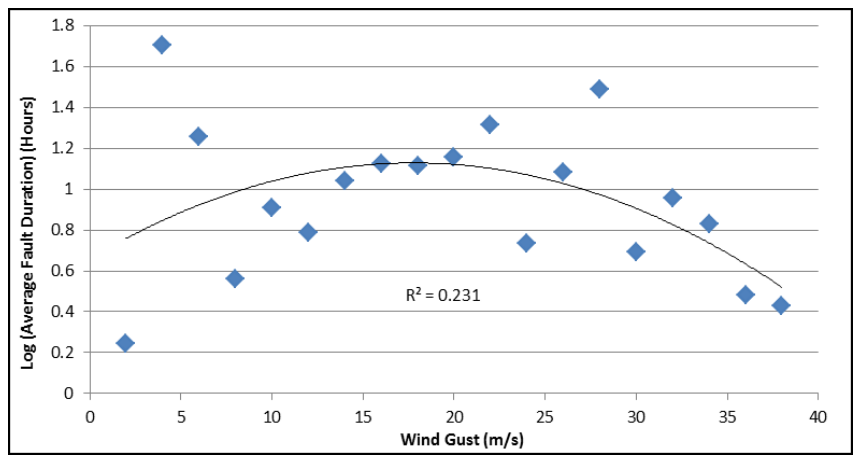

Fig. 8. Relationship between Log (Average Fault Duration) and 10meter Wind Gust

Fig. 8 shows only faults that had a RTS time longer than an hour against wind gust values. From Fig. 8 it can been see that there is more of relationship between fault duration and wind gusts, though like the small RTS time the extreme fault duration values tend to skew the results. There will need to be more investigation into this area to understand if there is a clear relationship between average fault duration and wind gusts. It may be that a more complex relationship exists than is tested here which may require a more complex model such as a two-stage model. This will require further investigation into a method that is able to quantify the impact on the system. However, it is expected that the RTS times will largely be affected by many non-meteorological factors (including availability of replacement equipment, and the logistics surrounding physically completing the repair) and so may never be suitably modelled without the inclusion of extensive additional data sets.

\section{CONCLUSIONS AND FURTHER WORK}

All power systems suffer from faults, and a significant percentage of them are caused by adverse weather. On the occasions that the system is hit by extreme weather, major damage to the system can be seen. If these adverse or extreme weather types occur more often, more frequent and rather long interruptions to supply of electricity can be expected. This paper has looked at the current effects of weather on the GB transmission network where it has been found that there is a 50/50 split of fault numbers, on average, between weather and non-weather faults and that the majority of weather faults occur on OHLs with 'one off 
events' that cause a number of faults within short period of time driving up the average number of faults a year.

Initial analysis has begun to develop the relationship between weather types and weather related faults with the main focus of this paper being on wind related faults. Using the historical fault data the relationship between wind gust and wind related faults was developed. This showed that the transmission system is able to deal with the lower wind gusts that are generally seen in GB but that the extreme or adverse values tend to cause faults. From this the probability of a wind fault occurring based on a wind gust occurrence was calculated. This showed that at the higher wind gusts values there was a much higher probability of a fault occurring, with the highest value being $58 \%$.

One suggested method of looking at the system impact was to investigate the relationship between RTS times and wind gust values, although on the first look there showed to be no clear relationship. However, when the smaller RTS times were removed a relationship started to develop. Further analysis will need to be undertaken to see if this will be able to be used as a possible method for quantifying the impact. These steps have shown initial analysis into developing relationships and probabilities for weather faults on the GB network. Work has already started on investigating the relationship between Convective Available Potential Energy (CAPE) and lightning related faults and relationships between snow related fault and possible measures of snow conditions - Snowfall, Snow Depth, Snow Density, or a combination of these.

Once developed this will be useful information for TNOs for future design, planning and operation of the network. The establishment of relationships between fault rates and wind, lightning and snow will give weather-fault relationships for $85 \%$ of weather related faults. Using these relationships, simulations can then be run for future weather scenarios, which will sample faults on the network and then run a series of load flows to determine the effects on the network due to the faults.

\section{ACKNOWLEDGEMENTS}

The contribution of the Power Networks Research Academy, and a number of companies including National Grid, Scottish Power and SSE, is gratefully acknowledged.

\section{REFERENCES}

[1] UKCIP, "What is climate change," [online] Available at: www.ukcip.org.uk/essentials/what-is-climate-change, 2012

[2] Jansen, E., J. Overpeck, K.R. Briffa, J.-C. Duplessy, F. Joos, V. Masson-Delmotte, D. Olago, B. Otto-Bliesner, W.R. Peltier, S. Rahmstorf, R. Ramesh, D. Raynaud, D. Rind, O. Solomina, R. Villalba, and D. Zhang, "Climate Change 2007: The Physical Science Basis. Contribution of Working Group I to the Fourth Assessment Report of the Intergovernmental Panel on Climate Change," Cambridge University Press: Cambridge, UK, 2007

[3] Gov, D, "Environment and greener living: Effects of climate change," [online] Available at: http://webarchive.nationalarchives.gov.uk, 2012.

[4] J. Sundell, D. Beck, F. György, K. Gustafsson, J. L. Harris, E. Herbert, A. Kapče, P. Lienhart, A. Maissis, I. Pierre, and K. Szynol,
"Impacts of Severe Storms on Electric Grids, Task Force on Power Outages", EURELECTRIC: Brussels, 2006.

[5] National Grid, "Adapting to Climate Change, Managing the Risks National Grid," [online] Available at: www.oursouthwest.com, 2010.

[6] Ofgem, "Adaptation to Climate Change: Report to Defra," [online] Available at: archive.defra.gov.uk, 2011.

[7] SSE Power Distribution. " Climate Change Adaptation Report," [online] Available at: http://archive.defra.gov.uk, 2011.

[8] B.Fleming, "Climate Change Adaption Report: Final Report", Scottish Power Energy Networks, 2011.

[9] Operations Directorate of Energy Networks Association "Electricity Networks Climate Change Adaptation Report," Energy Networks Association, 2011.

[10] H. Thornton, L. McColl, "Investigating the Relationship between Electricity Network Resilience and Weather. EP2 - The Impact of Climate Change on the UK Energy Industry", Met Office UK, [online] Available at: www.ep2.org.uk, 2008.

[11] E. Palin, L. McColl, "Baseline Climate Risk Assessment for the Electricity Network: National Grid.” Met Office UK, 2010.

[12] E Palin, L McColl, "Future Climate Risk Assessment for the Electricity Network: National Grid," Met Office UK, 2010.

[13] D. Ward, "The effect of weather on grid systems and the reliability of electricity supply," Climatic Change, vol. 121, no. 1, pp. 103-113, 2013.

[14] D. O. Koval, S. Bin, S. Shen, and A. A. Chowdhury, "Modeling Severe Weather Related High Voltage Transmission Line Forced Outages" IEEE PES Transmission and Distribution Conference and Exhibition, 21-24 May 2006.

[15] Met Office UK, "MetDB Land SYNOP data," NCAS British Atmospheric Data Centre, [online] Available at: badc.nerc.ac.uk, 2008.

[16] Met Office UK, "Met Office Integrated Data Archive System (MIDAS) Land and Marine Surface Stations Data (1853-current)," NCAS British Atmospheric Data Centre, [online] Available at: badc.nerc.ac.uk, 2012.

[17] European Centre for Medium-Range Weather Forecasts (ECMWF), "ERA Interim, Daily fields," [online] Available at: www.ecmwf.int/research/era/do/get/index, 2006.

[18] D. P. Dee, S. M. Uppala, A. J. Simmons, P. Berrisford, P. Poli, S. Kobayashi, U. Andrae, M. A. Balmaseda, G. Balsamo, P. Bauer, P. Bechtold, A. C. M. Beljaars, L. van de Berg, J. Bidlot, N. Bormann, C. Delsol, R. Dragani, M. Fuentes, A. J. Geer, L. Haimberger, S. B. Healy, H. Hersbach, E. V. Hólm, L. Isaksen, P. Kallberg, M. Köhler, M. Matricardi, A. P. McNally, B. M. Monge-Sanz, J-J, Morcrette, BK. Park, C. Peubey, P. de Rosnay, C. Tavolato, J-N. Thépaut, F. Vitart, "The ERA-Interim reanalysis: configuration and performance of the data assimilation system." Quarterly Journal of the Royal Meteorological Society, vol 137, no. 656, pp. 553-597, 2011. 